\title{
Effect of sevoflurane and propofol on tourniquet-induced endothelial damage: a pilot randomized controlled trial for knee- ligament surgery
}

Felipe Maldonado ${ }^{1}$, Diego Morales², Rodrigo Gutiérrez ${ }^{1,3}$, Maximiliano Barahona ${ }^{4}$, Oscar Cerda ${ }^{2,5,6}$ and Mónica Cáceres ${ }^{2,5,6^{*}}$

\begin{abstract}
Background: The glycocalyx layer is a key structure in the endothelium. Tourniquet-induced ischemic periods are used during orthopedic surgery, and the reactive oxygen species generated after ischemia-reperfusion may mediate the shedding of the glycocalyx. Here, we describe the effects of tourniquet-induced ischemia-reperfusion and compare the effects of sevoflurane and propofol on the release of endothelial biomarkers after ischemia-reperfusion in knee-ligament surgery.
\end{abstract}

Methods: This pilot, single-center, blinded, randomized, controlled trial included 16 healthy patients. After spinal anesthesia, hypnosis was achieved with sevoflurane or propofol according to randomization. During the perioperative period, five venous blood samples were collected for quantification of syndecan-1, heparan sulfate, and thrombomodulin from blood serum by using ELISA assays kits. Sample size calculation was performed to detect a 25\% change in the mean concentration of syndecan-1 with an alpha of 0.05 and power of $80 \%$.

Results: For our primary outcome, a two-way ANOVA with post-hoc Bonferroni correction analysis showed no differences in syndecan-1 concentrations between the sevoflurane and propofol groups at any time point. In the sevoflurane group, we noted an increase in syndecan-1 concentrations 90 min after tourniquet release in the sevoflurane group from $34.6 \pm 24.4 \mathrm{ng} / \mathrm{mL}$ to $47.9 \pm 29.8 \mathrm{ng} / \mathrm{mL}$ (Wilcoxon test, $p<0.01$ ) that was not observed in patients randomized to the propofol group. The two-way ANOVA showed no intergroup differences in heparan sulfate and thrombomodulin levels.

Conclusions: Superficial endothelial damage without alterations in the cell layer integrity was observed after tourniquet knee-ligament surgery. There was no elevation in serum endothelial biomarkers in the propofol group patients. Sevoflurane did not show the protective effect observed in in vitro and in vivo studies.

(Continued on next page)

\footnotetext{
* Correspondence: monicacaceres@med.uchile.cl

${ }^{2}$ Program of Cellular and Molecular Biology, Institute of Biomedical Sciences

(ICBM), Faculty of Medicine, Universidad de Chile, Santiago, Chile

${ }^{5}$ Millennium Nucleus of Ion Channels-Associated Diseases (MiNICAD),

Santiago, Chile

Full list of author information is available at the end of the article
}

(c) The Author(s). 2020 Open Access This article is licensed under a Creative Commons Attribution 4.0 International License, which permits use, sharing, adaptation, distribution and reproduction in any medium or format, as long as you give appropriate credit to the original author(s) and the source, provide a link to the Creative Commons licence, and indicate if changes were made. The images or other third party material in this article are included in the article's Creative Commons licence, unless indicated otherwise in a credit line to the material. If material is not included in the article's Creative Commons licence and your intended use is not permitted by statutory regulation or exceeds the permitted use, you will need to obtain permission directly from the copyright holder. To view a copy of this licence, visit http://creativecommons.org/licenses/by/4.0/. The Creative Commons Public Domain Dedication waiver (http://creativecommons.org/publicdomain/zero/1.0/) applies to the data made available in this article, unless otherwise stated in a credit line to the data. 
(Continued from previous page)

Trial registration: The trial was registered in www.clinicaltrials.gov (ref: NCT03772054, Registered 11 December 2018).

Keywords: Syndecan-1, Heparan sulfate, Thrombomodulin, Ischemia reperfusion, Ligament reconstruction

\section{Background}

The glycocalyx layer is a key structure in the regulation of the endothelium. Its dynamic composition results from structural modifications mediated by circulating molecules [1]. A highly sulfated matrix of glycosaminoglycans bound to proteoglycans and glycoproteins acts as a pre-endothelial barrier for macromolecules such as albumin $[2,3]$, adding a chemical interaction component to the fluid-molecular exchange between blood and the interstitial space $[4,5]$. Hence, the interaction with endothelial cells beneath the sub-glycocalyx space creates the endothelial barrier [5].

Loss of the glycocalyx leads to an increase in fluid permeability, interstitial edema, acceleration of leucocyte and platelet adhesion, and coagulation disorders $[5,6]$. The endothelial damage is now recognized as the hallmark of different pathologies $[2,7]$ and is associated with worse outcomes in acute coronary syndrome $[8,9]$, acute distress respiratory syndrome [10], and sepsis [11].

Perioperative fluid infusions, together with focal and global ischemic episodes, are related to the release of glycocalyx components into the circulation. $[4,12]$. Kneeligament reconstruction surgery with a femoral tourniquet generates a brief ischemic period that enhances the surgical field and prevents major blood loss. A transient ischemia-reperfusion (IR) state is generated after the tourniquet is released. Since reactive oxygen species (ROS) generated after IR mediate the shedding of the endothelial glycocalyx, [13, 14], this surgical scenario predisposes patients to endothelial damage.

Sevoflurane, a general anesthetic, has shown protective endothelial effects both in-vitro and in animal models of IR injury [12, 15-20]. Conversely, propofol does not show this effect and it may further increase the glycocalyx structure damage [4].

We propose that the use of the anesthetic sevoflurane will reduce the IR-induced superficial endothelial damage in comparison with propofol. To test this, we planned a pilot trial to compare the differences in the levels of the superficial endothelial damage biomarker syndecan-1 after tourniquet-induced IR in the presence of general anesthetics. In the same samples, we measured heparan sulfate and thrombomodulin concentrations as additional biomarkers of superficial and profound endothelial damage.

\section{Methods}

Trial design

We conducted a single-center, randomized, controlled trial with two parallel groups. The trial was approved by the Ethics committee of the Hospital Clínico Universidad de Chile, José Joaquin Aguirre and was conducted according to the principles of the Helsinki Declaration under monitoring by the Good Clinical Practice unit of our institution. Written informed consent was obtained from all patients before they were included in the trial. The outcome assessors were blinded to the group allocation of the patients. This study adhered to CONSORT guidelines for reporting randomized trials [21].

\section{Participants}

We included 16 patients scheduled to undergo elective knee-ligament reconstruction surgery with at least 60 min of tourniquet-induced ischemia of one of the lower extremities at the Hospital Clínico de la Universidad de Chile. The inclusion criteria were age between 18 and 60 years and an American Society of Anesthesiologists (ASA) classification I and II. We excluded patients with allergies to egg or soya, previous history of critical events during surgery and the perioperative period, those at risk of malignant hyperthermia, and patients with 3 or more predictors of difficult airway management.

\section{Interventions}

Blood samples were collected with the informed consent of the patients. All patients entered the operating room and after standard ASA monitorization and placement of an intravenous line (IV), a $50 \mathrm{~mL} \cdot \mathrm{h}^{-1}$ Ringer lactate infusion was started. All additional drugs were bolus administered and pushed with $10 \mathrm{~mL}$ saline solution. Spinal anesthesia was performed under $1 \mathrm{mg}$ midazolam and $1 \mu \mathrm{g} \mathrm{kg}^{-1}$ fentanyl sedation. After analgesia and motor block establishment, another mg of midazolam was administered, and according to the study arm allocation, an intravenous or inhalation hypnosis-induction was performed. The airway was secured by laryngeal mask placement before the surgery started. A femoral tourniquet was installed and inflated by the surgeon 120 $\mathrm{mmHg}$ above patient systolic blood pressure. Surgery and tourniquet duration, total fluid administration, and the use of vasoactive agents were registered. The sevoflurane group hypnotic anesthetic target was 0.8-1.0 age-corrected minimum alveolar concentration (MAC) 
and the propofol hypnotic anesthetic target was set to a site-effect target-controlled infusion of $2-2.5 \mu \mathrm{g} \cdot \mathrm{mL}^{-1}$ (Marsh, keO $1.21 \mathrm{~min}^{-1}$ ). Both targets allow spontaneous ventilation or pressure support ventilation during surgery. Finally, a femoral nerve block for postoperative analgesia was performed in the post-anesthesia care unit for all patients.

\section{Blood samples}

To measure endothelial damage biomarkers, five different venous blood samples were collected: at the IV placement (baseline value, T1); during surgery before tourniquet release (T2); and 10 (T3), 60 (T4), and 90 (T5) minutes after tourniquet release. At the end of surgery, all patients were transferred to a post-operative care unit where the blood samples were collected. All blood samples were collected by the anesthesiologist team and coded before delivering them to the processing laboratory. Blood samples were incubated for one hour at $37^{\circ} \mathrm{C}$ and centrifuged at $1500 \mathrm{rpm}$ for $10 \mathrm{~min}$. Blood serum was stored in a $-80^{\circ} \mathrm{C}$ freezer for final analysis.

\section{Elisa}

To characterize the endothelial damage, we decided to measure two superficial biomarkers (syndecan-1 and heparan sulfate) and one deep biomarker (thrombomodulin). To evaluate the biomarker levels in blood serum, we used the following assays: syndecan-1 (CD138) Human ELISA Kit (Catalog \#ab46506, Abcam, Cambridge, MA, USA), Heparan Sulfate BioAssay ${ }^{\text {Tx }}$ ELISA kit (Cata$\log \# 356350$, USBiological, Salem, MA, USA), and human Thrombomodulin ELISA kit (Catalog \#CSBE07937h, CUSABIO, Houston, TX, USA). All measurements were performed in duplicate. Assays and analyses were conducted according to the manufacturer's instructions. Standard solutions of syndecan-1, heparan sulfate, and thrombomodulin were provided in each test, with a detection range of $8 \mathrm{ng} / \mathrm{mL}$ to $256 \mathrm{ng} / \mathrm{mL}$ for syndecan$1,78 \mathrm{ng} / \mathrm{mL}$ to $5 \mu \mathrm{g} / \mathrm{mL}$ for heparan sulfate, and 0.312 $\mathrm{ng} / \mathrm{mL}$ to $20 \mathrm{ng} / \mathrm{mL}$ for thrombomodulin.

\section{Outcomes}

The primary outcome was the difference in syndecan-1 concentrations between sevoflurane and propofol groups $90 \mathrm{~min}$ after tourniquet release (T5). Heparan sulfate and thrombomodulin blood serum concentrations were compared between both groups as secondary outcomes. All the comparisons were assessed at the pre-established five points during the perioperative period.

\section{Sample size}

We based our sample size calculation on the normal range values of syndecan-1 reported by Rahbar et al. and on the increase in syndecan-1 levels reported in cardiac surgery patients, septic patients, and trauma injured patients [11, 12, 22]. These findings describe an increase of two or three times to several folds from baseline values. Considering a normal syndecan- 1 value of $31.6 \mathrm{ng} / \mathrm{mL}$, a standard deviation of $15.3 \mathrm{ng} / \mathrm{mL}$, and a three-fold increase from the normal range values, a sample size calculation was performed to detect a $25 \%$ change in the mean concentration of syndecan- 1 with an alpha of 0.05 and a power of $80 \%$. Considering a $20 \%$ loss of patients, 16 patients (8 patients per arm) were needed for the two-sided test analysis.

\section{Randomization}

Computer-generated permuted eight-block randomization was performed. With the results, sixteen consecutively sealed and numbered envelopes were generated. Each envelope was opened consecutively after each patient signed the informed consent form. Blood tubes were then labelled with unique patient and sample codes. Sample collectors carried each tube from the operating room to the processing laboratory for analysis.

\section{Blinding}

Sample collectors, laboratory processing investigators, and the outcome assessor were blinded to patients' allocations. After study termination, the outcome assessor had access to the patient's sample codes and performed the final analysis.

\section{Statistical methods}

Categorical variables were summarized as relative frequencies. Continuous variables for primary and secondary variables were expressed as the mean and standard deviation (SD) or interquartile rank (IQR). Non-paired results were compared with the Mann-Whitney test. For comparison of repeated assessments, we used a two-way ANOVA. Post-hoc comparisons with baseline values were performed with a Bonferroni correction. For paired data, a Wilcoxon test was performed. Two-tailed $P$ values less than 0.05 were considered significant. Data were analyzed with GraphPad Prism software, version 8.0 (La Jolla, CA, USA).

\section{Results}

\section{Participant flow and recruitment}

Between December 2018 and July 2019, 16 subjects were consecutively randomized to each of the two arms and analyzed for the primary outcome. There were no exclusions or subject losses in either group (Fig. 1).

\section{Baseline data}

Demographic characteristics are presented in Table 1 . There were no differences in age, ASA score, and body mass index. All patients had comparable tourniquet time 


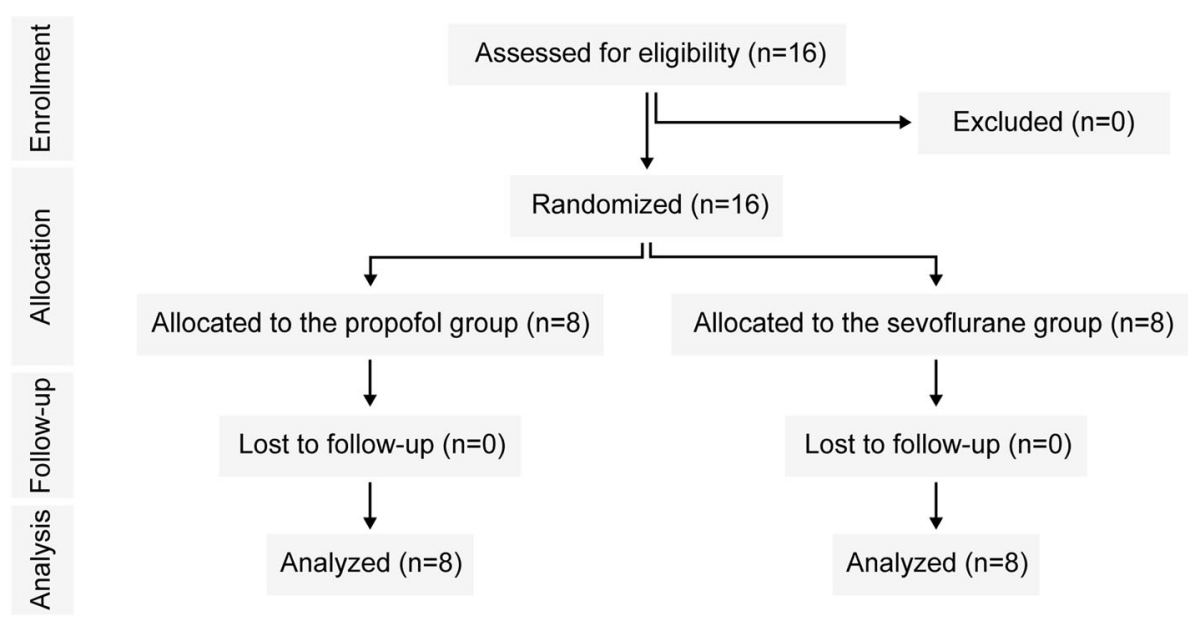

Fig. 1 CONSORT diagram

(96 \pm 24 min, Mann-Whitney test, $p=0.59$ ) and fluid administration $(124 \pm 47 \mathrm{~mL}$, Mann Whitney, $p=0.08)$ during surgery. Although there was a higher need for ephedrine in the sevoflurane group, this difference was not significant. One patient required $200 \mu \mathrm{g}$ of phenylephrine. Blood loss during surgery was described as minimum in all cases. Baseline syndecan-1 concentrations were $34.61 \pm 24.4 \mathrm{ng} / \mathrm{mL}$ in the sevoflurane group and $27.02 \pm 12.61 \mathrm{ng} / \mathrm{mL}$ in the propofol group.

\section{Outcomes}

\section{Main outcome (syndecan-1)}

Our primary outcome was the difference in the syndecan-1 concentrations between sevoflurane and propofol groups. In a two-way ANOVA with Bonferroni correction, we found no differences in the plasma levels of syndecan-1 between the sevoflurane and propofol groups at any time. However, when we analyzed the changes in syndecan-1 levels across different times in each group, we found that the syndecan-1 level was elevated 90 min after tourniquet release in comparison to the baseline values in the sevoflurane group (from $34.6 \pm 24.4 \mathrm{ng} / \mathrm{mL}$ to $47.9 \pm$ $29.8 \mathrm{ng} / \mathrm{mL}$, Wilcoxon test, $p<0.01)$. This increase was not found in the propofol group (Fig. 2).

\section{Secondary outcomes (heparan sulfate and thrombomodulin)}

Heparan sulfate and thrombomodulin did not differ significantly between groups at the time points evaluated (Fig. 3).

\section{Other analysis}

Our power analysis allowed us to identify differences in the syndecan-1 concentration, and we performed a pooled examination of our cohort's data to describe the

Table 1 Patient characteristics. Baseline and surgical characteristics of patients randomized to the sevoflurane and propofol groups. BMI (body mass index), ASA (American Society Association), n (number of subjects), Standard deviation (SD)

\begin{tabular}{|c|c|c|c|}
\hline & Total (SD) $(\boldsymbol{n}=16)$ & $\begin{array}{l}\text { Propofol (SD) } \\
(\boldsymbol{n}=8)\end{array}$ & $\begin{array}{l}\text { Sevoflurane (SD) } \\
(\mathrm{n}=8)\end{array}$ \\
\hline Age & $27(9)$ & $25(6)$ & $30(11)$ \\
\hline BMI & $28(4)$ & $27(4)$ & $29(5)$ \\
\hline \multicolumn{4}{|l|}{ ASA Score (n) } \\
\hline 1 & 11 & 5 & 6 \\
\hline 2 & 5 & 3 & 2 \\
\hline Tourniquet Time (min) & $96(24)$ & $91(17)$ & $101(30)$ \\
\hline Fluid dose $(\mathrm{mL})$ & $124(47)$ & $105(33)$ & $144(52)$ \\
\hline Number of patients with need of Ephedrine & 8 & 3 & 5 \\
\hline Ephedrine dose (mg) & $23(17)$ & $14(9)$ & $28(19)$ \\
\hline Number of patients with need of Phenylephrine & 1 & 0 & 1 \\
\hline Phenylephrine dose (mg) & 200 & 0 & 200 \\
\hline
\end{tabular}




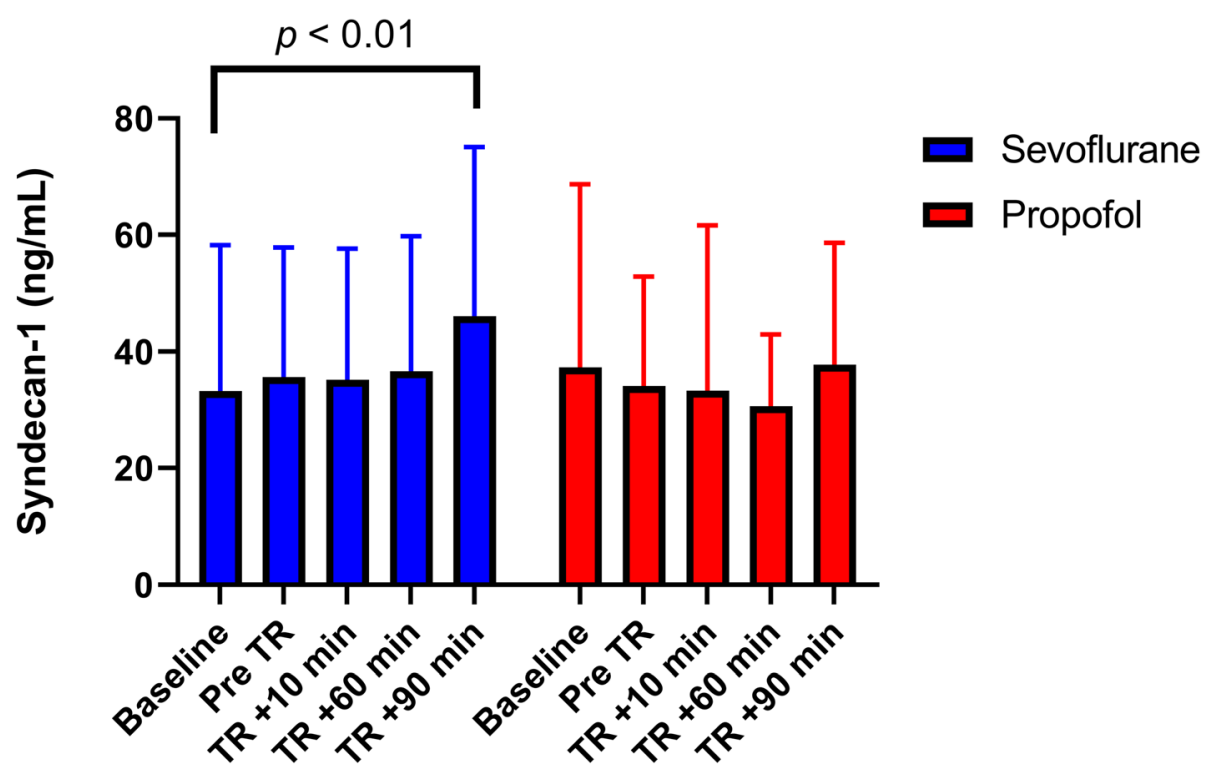

Fig. 2 Endothelial damage biomarkers differences between sevoflurane and propofol groups. Endothelial damage was observed as an increase in the syndecan-1 concentration in the sevoflurane group. The difference was significant from baseline values at 90 min after tourniquet release (Wilcoxon test, $\mathrm{p}<0.01$ ). There was no difference between sevoflurane and propofol groups

behavior of perioperative serum biomarkers in this surgery. We observed a baseline syndecan-1 concentration of $30.9 \pm 19.6 \mathrm{ng} / \mathrm{mL}$ and a non-significant increase in the concentration during surgery over the next $60 \mathrm{~min}$ following tourniquet release. After $90 \mathrm{~min}$ (T5), a 37\% increase in syndecan-1 concentration was observed $(42.7 \pm 25.5 \mathrm{ng} / \mathrm{mL}$; Wilcoxon test, $p<0.001)$. This increase was also significantly different from all the other sampling periods (one-way ANOVA, T5 vs. T2, $p=$ 0.013 ; T5 vs. T3, $p=0.019$, T5 vs. T4, $p=0.013$ ). Baseline heparan sulfate concentration was $919.4 \pm 1579.8$ $\mathrm{ng} / \mathrm{mL}$. Like syndecan -1 , heparan sulfate concentration increased after tourniquet release, and after $60 \mathrm{~min}$ a $58 \%$ increase was reached $(1588.7 \pm 1692.1 \mathrm{ng} / \mathrm{mL}$, Wilcoxon test, $p=0.036$ ). This elevated concentration remained at $90 \mathrm{~min}$ after tourniquet release, but there were no significant differences from baselines values. In contrast to the elevations of both superficial endothelial biomarkers, thrombomodulin levels did not show any elevation during the perioperative period.

Finally, to estimate whether the anesthetic choice modifies the amount of each biomarker released during the study protocol, an area under the curve analysis was performed. Sevoflurane and propofol showed no differences in the levels of biomarker released during the study (syndecan-1, sevoflurane: $5836 \mathrm{ng}$ [IQR: 3264$8829 \mathrm{ng}$ ], propofol: $5596 \mathrm{ng}$ [IQR: 2319-7202], MannWhitney test, $p=0.295$; heparan sulfate, sevoflurane: $224407 \mathrm{ng}$ [IQR: $147003-315,892 \mathrm{ng}$ ], propofol: 127677 ng [IQR: 36996-291,879], Mann-Whitney test, $p=0.257$; thrombomodulin, sevoflurane: $34 \mathrm{ng}$ [IQR: $10-87 \mathrm{ng}$ ], propofol: $4.8 \mathrm{ng}$ [IQR: 0-34], Mann-Whitney test, $p=$
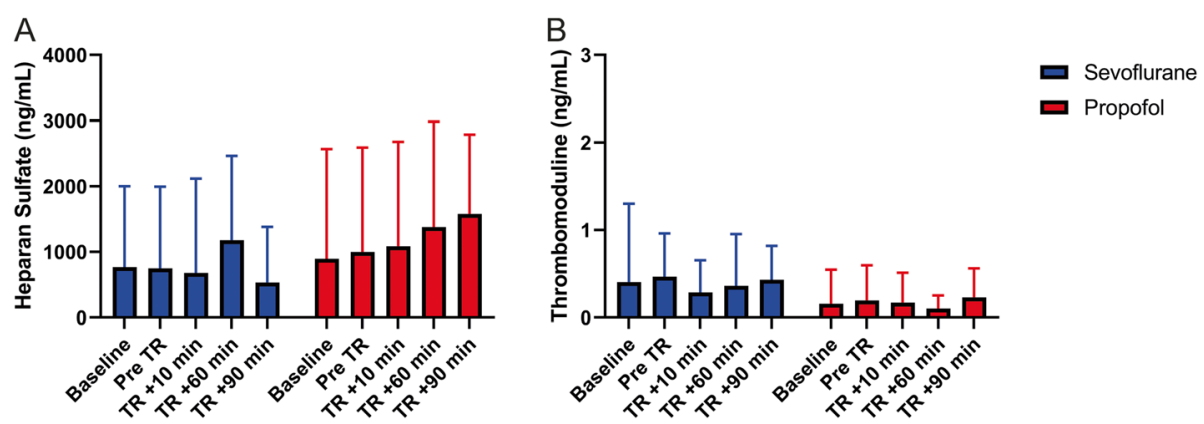

Fig. 3 Heparan sulfate and thrombomodulin differences between sevoflurane and propofol groups. Endothelial damage measured by heparan sulfate (a) did not show differences in the serum concentration at any time point. The endothelial cell integrity was similar in both groups as thrombomodulin did not show serum elevation (b) 
0.058) (Fig. 4). A significant difference was observed in the amount of thrombomodulin released in the propofol group after correcting the results by ischemic-tourniquet time (thrombomodulin, sevoflurane: $17 \mathrm{ng}$ [IQR: 2-63 ng], propofol: $0.2 \mathrm{ng}$ [IQR: 0-9], Mann-Whitney test, $p=0.020$ ).

\section{Adverse effects}

There were no adverse or unintended effects observed in the subjects.

\section{Discussion}

In the present article, we used a serum biomarker measurement approach to evaluate the protective effect of two common anesthetics used in clinical practice on the endothelial glycocalyx-cell integrity after a tourniquetinduced ischemia-reperfusion period. The presence of circulating syndecan-1 and heparan sulfate, both components of the glycocalyx, was used as a marker of early superficial endothelial damage. Thrombomodulin, a profound endothelial damage marker, was used for quantification of cell layer damage in the endothelium $[8,10]$.

We observed an increase in superficial-endothelial damage biomarkers after tourniquet release in subjects randomized to sevoflurane that were not observed in the propofol group. The pooled analysis shows that both syndecan-1 and heparan sulfate levels were elevated after tourniquet release in knee ligament surgery. Interestingly, although thrombomodulin biomarker concentrations did not increase, the AUC analysis showed a significant difference in the amount of the biomarker released between groups. This may imply that endothelial cell damage may occur and may be affected by anesthetics. More studies will be needed to confirm this observation.

The reported normal values for plasma syndecan- 1 are in the range of 0 to $300 \mathrm{ng} / \mathrm{mL}$, while those for heparan sulfate range from 4820 to $7940 \mathrm{ng} / \mathrm{mL}$. The study by
Rehm et al. found a basal plasma syndecan value of 12 $\mathrm{ng} / \mathrm{mL}$ and $5900 \mu \mathrm{g} / \mathrm{mL}$ for heparan sulfate [12]. The study by Johansen et al. in septic patients describes a normal range of serum syndecan- 1 of $51 \pm 12 \mathrm{ng} / \mathrm{mL}$ and a range of $4.5 \pm 0.8 \mathrm{ng} / \mathrm{mL}$ for thrombomodulin[11]. The study by Rahbar et al. reported that the reference syndecan-1 value in healthy volunteers provided by Abcam was $31.6 \pm 15.3 \mathrm{ng} / \mathrm{mL}$ [22]. Our results showed baseline syndecan- 1 concentrations of $34.61 \pm 24.4 \mathrm{ng} /$ $\mathrm{mL}$ in the sevoflurane group and $27.02 \pm 12.61 \mathrm{ng} / \mathrm{mL}$ in the propofol group, both of which were within the range of previous reports $[11,22]$. In the study by Rehm et al., cardiopulmonary bypass during ascending aorta surgery, infrarenal aortic aneurysm, and circulatory arrest resulted in a several-fold increase in the levels of endothelial damage biomarkers. In our work, we found that the transient ischemic period of a lower extremity induced a $37 \%$ increase in syndecan-1 levels. This may be explained by the substantially less ischemic tissue than in the cardiac surgery scenario.

In vitro and in vivo studies have suggested that sevoflurane anesthesia has a glycocalyx protective effect [4, 13, 15-18, 23, 24]. Recently, Kim et al. compared the effects of sevoflurane and propofol in 78 patients who underwent thoracic surgery [25]. They found an increase in the heparan sulfate and syndecan-1 plasma concentrations during one-lung ventilation surgery. Although there was an increase in both biomarkers, there was no significant difference in anesthetic groups. These findings are consistent with our study since we found no differences between the sevoflurane and propofol groups. Nevertheless, we observed that syndecan-1 levels were significantly higher in the sevoflurane group in comparison with the baseline values and, this was not observed in the propofol group. Moreover, the sevofluraneassociated increases in syndecan-1 levels accounted for the main component of the increment observed in the pooled data.
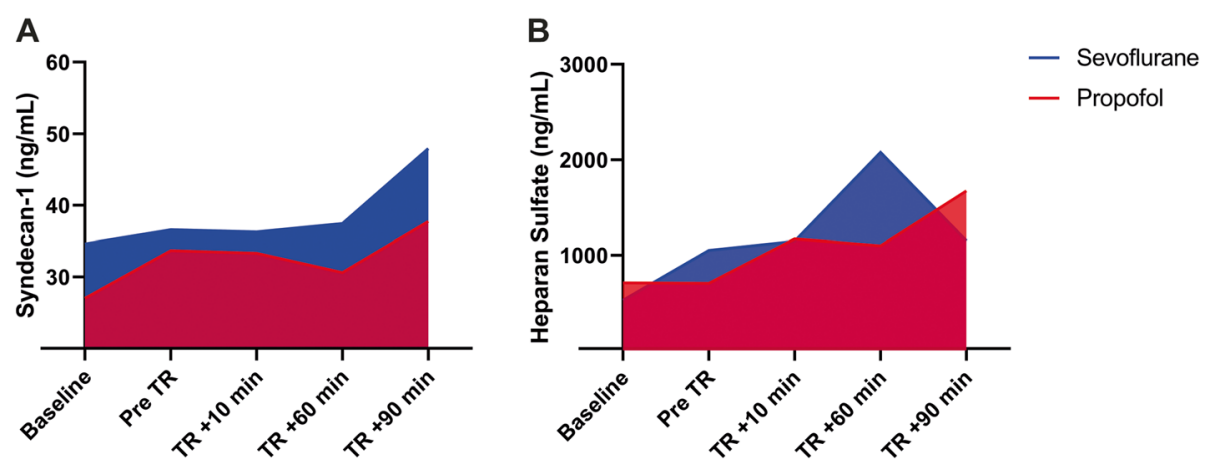

Fig. 4 Area under curve for syndecan-1 and heparan sulfate during the perioperative period. Representation of the area under the curve analysis. Amounts of Syndecan-1 (a) and Heparan sulfate (b) released in the sevoflurane and propofol groups during the study protocol. Anesthetics showed no differences in the levels of biomarker released during the study 
Thrombomodulin is a cell transmembrane glycoprotein marker of endothelial disruption. Its liberation into plasma is a predictor of multiorgan failure and death [11]. Since thrombomodulin elevation reflects profound endothelial damage, we were able to separate the endothelial layer impact of the ischemia-reperfusion insult and verify that it mainly affected the glycocalyx layer.

There are a few interventions that may reduce glycocalyx-endothelial damage. Limiting the fluid administration and use of methylprednisolone has been shown to reduce the elevation of syndecan-1 levels [26-28]. We limited our fluid infusion to an arbitrary low dose of 50 $\mathrm{mL} \cdot \mathrm{h}^{-1}$ in both groups and we avoided the use of any corticosteroid as an antiemetic during the perioperative blood sampling period. With this strategy, we did not observe a significant elevation in any biomarker level before the tourniquet release during surgery. This approach may be suitable for all surgeries where no fluid loss is expected.

Many insults that increase the endothelial damage are related to a surgical scenario. Procedures such as cardiac surgery with extracorporeal circulation [29], fluid administration [30,31], and one-lung ventilation [19] are performed under general anesthesia, so the studies identifying the best pharmacologic approaches are crucial. Various anesthetics have been studied for their potential protective effect. In vitro and in vivo models have demonstrated the protective effect of sevoflurane against ROS on the endothelium [13, 15, 17, 18, 23]. Propofol did not show a protective effect; moreover, one study on isolated guinea pig hearts reported an increase in syndecan-1 levels after $20 \mathrm{~min}$ of ischemia [4]. These findings have been difficult to translate to clinical practice since the protective effect of sevoflurane observed in different organ studies has not been observed in patients [25].

We use a novel model for studying tourniquetinduced endothelial damage. We found no previous studies in the knee-traumatological scenario. Moreover, knee-ligament surgery has not been described before as a procedure leading to endothelial damage. Most articles report that a collapsed lung during one-lung ventilation surgery generates an elevated inflammatory response with increased production of ROS [19, 20, 23]. Here, we describe that the ischemic insult after tourniquet release is enough to induce a biomarker signal of injury. Our cohort was composed of healthy ASA I and II subjects in which this surgery involves little morbidity per se. Since syndecan-1 elevation observed in septic and critical care patients are associated with higher morbidity and mortality, is relevant to find an adequate strategy to avoid endothelial destruction as it is implicated in tissue edema, coagulopathy, and organ dysfunction as a great number of critical patients would need surgery.
Anesthetic selection may be crucial in their treatment if there are insults that generate ROS and endothelial damage.

\section{Limitations}

Here, we compare the effects of two common anesthetics on endothelial damage. We analyzed five different points, covering the perioperative period. We found that the increase in Syndecan-1 levels at $90 \mathrm{~min}$ posttourniquet release was the clearest moment to detect differences with baseline values. This work has several limitations. First, we included a small population sample (16 patients) that allowed us to detect a $25 \%$ change in the mean concentration of syndecan- 1 , and a broader sample may be necessary to detect smaller differences and confirm our findings. Another limitation is that we decided to compare general anesthetics in addition to a spinal technique. In this scenario, we do not know how spinal anesthesia and the related vasodilation may impact the reperfusion phenomenon or if this shows a markedly significant difference between the two groups. We used only one type of surgery assuming that the ischemic insult of one extremity may be enough to elicit post-ischemic-reperfusion ROS generation and systemic endothelial damage. Since this is a rapid phenomenon, we decided to measure biomarker concentrations in the early reperfusion periods until $90 \mathrm{~min}$ post tourniquet release. Although we observed an increase in biomarker levels at $90 \mathrm{~min}$ after tourniquet release, studies of biomarker concentrations further in time may have helped us understand if syndecan-1 levels show more differences between groups, and this may have strengthened our results. Finally, a measure of ROS may be crucial to establish a correlation between both reperfusion and biomarker release.

\section{Conclusions}

Contrary to our hypothesis, patients in the sevoflurane group showed an increase in the serum concentration of syndecan-1. Our results indicate that the use of propofol as a hypnotic may be a reasonable choice during kneeligament surgery and in association with limited fluid administration may have minimal effect on the endothelium.

Finally, we observed that after periods of ischemiareperfusion in lower extremities induced by a tourniquet, there was an increase in the serum concentrations of syndecan-1 and heparan sulfate, but not thrombomodulin. This may reflect superficial endothelial damage without alterations in the cell layer integrity. Sevoflurane did not show the protective effect observed in in vitro and in vivo studies. 


\section{Abbreviations}

ASA: American Society Association; IQR: Interquartile rank; IR: Ischemiareperfusion; IV: Intravenous line; MAC: Minimum Alveolar Concentration; ROS: Reactive oxygen species; SD: Standard deviation

\section{Acknowledgments}

Not applicable.

\section{Authors' contributions}

FM: Conceptualization, study design, data collection, data analysis, writing of the original draft, review, edit, approval of the final manuscript and funding acquisition. DM: Data collection, data analysis, writing of the original draft, review, edit and approval of the final manuscript. RG: Data collection, writing of the original draft, review, edit and approval of the final manuscript. MB: Data collection, data analysis, writing of the original draft, review, edit and approval of the final manuscript. OC: Study design, data analysis, writing of the original draft, review, edit and approval of the final manuscript. MC: Study design, data collection, data analysis, writing of the original draft, review, edit, approval of the final manuscript and funding acquisition. The author(s) read and approved the final manuscript,

\section{Funding}

This work was supported by the 2016 Second Investigation Grant of the Faculty of Medicine, Universidad de Chile, Santiago, Chile (FM) and a grant from the National Fund for Science and Technology (Fondecyt) Grant 1181283 (MC)

\section{Availability of data and materials}

The datasets used and/or analyzed during the current study are available from the corresponding author on reasonable request.

\section{Ethics approval and consent to participate}

The trial was approved by Ethics committee of the Hospital Clínico de la Universidad de Chile (Ref: OAIC 903/17). Written Informed consent was obtained from all patients before being included in the trial.

\section{Consent for publication}

Not applicable.

\section{Competing interests}

The authors declare that they have no competing interests.

\section{Author details}

'Department of Anesthesia and Perioperative Medicine. Hospital Clínico de la Universidad de Chile. Faculty of Medicine, Universidad de Chile, Santiago, Chile. ${ }^{2}$ Program of Cellular and Molecular Biology, Institute of Biomedical Sciences (ICBM), Faculty of Medicine, Universidad de Chile, Santiago, Chile. ${ }^{3}$ Centro de Investigación Clínica Avanzada (CICA), Hospital Clínico de la Universidad de Chile. Faculty of Medicine, Universidad de Chile, Santiago, Chile. ${ }^{4}$ Department of Orthopaedic Surgery, Faculty of Medicine, Universidad de Chile, Santiago, Chile. ${ }^{5}$ Millennium Nucleus of Ion Channels-Associated Diseases (MiNICAD), Santiago, Chile. ${ }^{6}$ The Wound Repair, Treatment and Health (WORTH) Initiative, Facultad de Medicina. Universidad de Chile, Independencia 1027, 8380453 Santiago, Chile.

Received: 4 February 2020 Accepted: 29 April 2020

Published online: 20 May 2020

\section{References}

1. Kolářová H, Ambrůzová B, Švihálková Šindlerová L, Klinke A, Kubala L. Modulation of endothelial glycocalyx structure under inflammatory conditions. Mediat Inflamm. 2014;2014. https://doi.org/10.1155/2014/694312.

2. Alphonsus CS, Rodseth RN. The endothelial glycocalyx: a review of the vascular barrier. Anaesthesia. 2014 Jul;69(7):777-84. https://doi.org/10.1111/ anae.12661

3. Bashandy GM. Implications of recent accumulating knowledge about endothelial glycocalyx on anesthetic management. J Anesth. 2015 Apr 1; 29(2):269-78. https://doi.org/10.1007/s00540-014-1887-6.

4. Annecke T, Rehm M, Bruegger D, Kubitz JC, Kemming Gl, Stoekelhuber M, Becker BF, Conzen PF. Ischemia-reperfusion-induced unmeasured anion generation and glycocalyx shedding: sevoflurane versus propofol anesthesia. J Investig Surg. 2012 May 22;25(3):162-8. https://doi.org/10.3109/ 08941939.2011 .618524

5. Thind GS, Zanders S, Baker JK. Recent advances in the understanding of endothelial barrier function and fluid therapy. Postgrad Med J. 2018; 94(1111):289-95. https://doi.org/10.1136/postgradmedj-2017-135125.

6. Chappell D, Dörfler N, Jacob M, Rehm M, Welsch U, Conzen P, Becker BF. Glycocalyx protection reduces leukocyte adhesion after ischemia/ reperfusion. Shock. 2010;34(2):133-9.

7. Reitsma S, Slaaf DW, Vink H, Van Zandvoort MA. Oude Egbrink MG. The endothelial glycocalyx: composition, functions, and visualization. Pflügers Archiv-European Journal of Physiology. 2007;454(3):345-59. https://doi.org/ 10.1007/s00424-007-0212-8.

8. Chan SH, Chen JH, Li YH, Lin LJ, Tsai LM. Increasing post-event plasma thrombomodulin level associates with worse outcome in survival of acute coronary syndrome. Int J Cardiol. 2006;111(2):280-5. https://doi.org/10.1016/ j.ijcard.2005.09.015.

9. Frydland M, Ostrowski SR, Møller JE, Hadziselimovic E, Holmvang L, Ravn HB, Jensen LO, Pettersson AS, Kjaergaard J, Lindholm MG, Johansson PI. Plasma concentration of biomarkers reflecting endothelial cell-and glycocalyx damage are increased in patients with suspected ST-elevation myocardial infarction complicated by cardiogenic shock. Shock. 2018;50(5):538-44. https://doi.org/10.1097/SHK.0000000000001123.

10. Sapru A, Calfee CS, Liu KD, Kangelaris K, Hansen H, Pawlikowska L, Ware LB, Alkhouli MF, Abbot J, Matthay MA. Nhlbi Ards network. Plasma soluble thrombomodulin levels are associated with mortality in the acute respiratory distress syndrome. Intens Care Med. 2015;41(3):470-8. https://doi. org/10.1007/s00134-015-3648-X.

11. Johansen ME, Johansson PI, Ostrowski SR, Bestle MH, Hein L, Jensen AL, Søe-Jensen P, Andersen MH, Steensen M, Mohr T, Thormar K. Profound endothelial damage predicts impending organ failure and death in sepsis. Semin Thromb Hemost. 2015;41(01):016-25). Thieme Medical Publishers. https://doi.org/10.1055/s-0034-1398377.

12. Markus Rehm, Dirk Bruegger, Frank Christ, Peter Conzen, Manfred Thiel, Matthias Jacob, Daniel Chappell, Mechthild Stoeckelhuber, Ulrich Welsch, Bruno Reichart, Klaus Peter, Bernhard F. Becker, (2007) Shedding of the Endothelial Glycocalyx in Patients Undergoing Major Vascular Surgery With Global and Regional Ischemia. Circulation 116 (17):1896-1906.

13. Kazuma S, Tokinaga Y, Kimizuka M, Azumaguchi R, Hamada K, Yamakage M. Sevoflurane promotes regeneration of the endothelial glycocalyx by upregulating sialyltransferase. J Surg Res. 2019;241:40-7. https://doi.org/10. 1016/j.jss.2019.03.018.

14. Rubio-Gayosso I, Platts SH, Duling BR. Reactive oxygen species mediate modification of glycocalyx during ischemia-reperfusion injury. Am J Physiology Heart Circ Physiol. 2006;290(6):H2247-56. https://doi.org/10.1152/ ajpheart.00796.2005.

15. Annecke T, Chappell D, Chen C, Jacob M, Welsch U, Sommerhoff CP, Rehm $\mathrm{M}$, Conzen PF, Becker BF. Sevoflurane preserves the endothelial glycocalyx against ischaemia-reperfusion injury. Br J Anaesth. 2010 Apr 1;104(4):41421. https://doi.org/10.1093/bja/aeq019.

16. Chappell D, Heindl B, Jacob M, Annecke T, Chen C, Rehm M, Conzen P, Becker BF. Sevoflurane reduces leukocyte and platelet adhesion after ischemia-reperfusion by protecting the endothelial glycocalyx. Anesthesiology. 2011;115(3):483-91. https://doi.org/10.1097/ALN. Ob013e3182289988

17. Chen C, Chappell D, Annecke T, Conzen P, Jacob M, Welsch U, Zwissler B, Becker BF. Sevoflurane mitigates shedding of hyaluronan from the coronary endothelium, also during ischemia/reperfusion: an ex vivo animal study. Hypoxia. 2016:4:81. https://doi.org/10.2147/HP.S98660.

18. Li J, Yuan T, Zhao X, LV GY, Liu HQ. Protective effects of sevoflurane in hepatic ischemia-reperfusion injury. Int J Immunopathol Pharmacol. 2016; 29(2):300-7. https://doi.org/10.1177/0394632016638346.

19. Lohser J, Slinger P. Lung injury after one-lung ventilation: a review of the pathophysiologic mechanisms affecting the ventilated and the collapsed lung. Anesth Analg. 2015;121(2):302-18. https://doi.org/10.1213/ANE. 0000000000000808

20. Slinger $P$, Kilpatrick B. Perioperative lung protection strategies in cardiothoracic anesthesia: are they useful? Anesthesiol Clin. 2012;30(4):60728. https://doi.org/10.1016/j.anclin.2012.07.001.

21. Moher D, Hopewell S, Schulz KF, Montori V, Gøtzsche PC, Devereaux PJ, Elbourne D, Egger M, Altman DG. CONSORT 2010 explanation and 
elaboration: updated guidelines for reporting parallel group randomised trials. Int J Surg. 2012;10(1):28-55. https://doi.org/10.1136/bmj.c869.

22. Rahbar E, Cardenas JC, Baimukanova G, Usadi B, Bruhn R, Pati S, Ostrowski SR, Johansson PI, Holcomb JB, Wade CE. Endothelial glycocalyx shedding and vascular permeability in severely injured trauma patients. J Transl Med. 2015;13(1):117.

23. Casanova J, Simon C, Vara E, Sanchez G, Rancan L, Abubakra S, Calvo A, Gonzalez FJ, Garutti I. Sevoflurane anesthetic preconditioning protects the lung endothelial glycocalyx from ischemia reperfusion injury in an experimental lung autotransplant model. J Anesth. 2016;30(5):755-62. https://doi.org/10.1007/s00540-016-2195-0

24. Sánchez-Pedrosa G, Vara Ameigeiras E, Casanova Barea J, Rancan L, Simón Adiego CM, Garutti MI. Role of surgical manipulation in lung inflammatory response in a model of lung resection surgery. Interact Cardiovasc Thorac Surg. 2018;27(6):870-7. https://doi.org/10.1093/icvts/ivy198.

25. Kim HJ, Kim E, Baek SH, Kim HY, Kim JY, Park J, Choi EJ. Sevoflurane did not show better protective effect on endothelial glycocalyx layer compared to propofol during lung resection surgery with one lung ventilation. J Thorac Dis. 2018;10(3):1468. https://doi.org/10.21037/jtd.2018.03.44.

26. Dostalova V, Astapenko D, Kraus J, Cerny V, Ticha A, Hyspler R, Radochova V, Paral J, Dostal P. The effect of fluid loading and hypertonic saline solution on cortical cerebral microcirculation and glycocalyx integrity. J Neurosurg Anesthesiol. 2019;31(4):434-43. https://doi.org/10.1097/ANA. 0000000000000528.

27. Lindberg-Larsen V, Ostrowski SR, Lindberg-Larsen M, Rovsing ML, Johansson $\mathrm{Pl}$, Kehlet $\mathrm{H}$. The effect of pre-operative methylprednisolone on early endothelial damage after total knee arthroplasty: a randomised, doubleblind, placebo-controlled trial. Anaesthesia. 2017;72(10):1217-24. https://doi. org/10.1111/anae.13983.

28. Woodcock TE, Woodcock TM. Revised Starling equation and the glycocalyx model of transvascular fluid exchange: an improved paradigm for prescribing intravenous fluid therapy. Br J Anaesth. 2012;108(3):384-94 https://doi.org/10.1093/bja/aer515.

29. Dekker NA, Veerhoek D, Koning NJ, van Leeuwen AL, Elbers PW, van den Brom CE, Vonk AB, Boer C. Postoperative microcirculatory perfusion and endothelial glycocalyx shedding following cardiac surgery with cardiopulmonary bypass. Anaesthesia. 2019;74(5):609-18. https://doi.org/10 1111/anae.14577.

30. Benes J, Cerny V. Fluid therapy and endothelial glycocalyx layer. On the track of the water-phobic Bigfoot. Minerva Anestesiol. 2018;84(9):1007. https://doi.org/10.23736/50375-9393.18.12811-2.

31. Hippensteel JA, Uchimido R, Tyler PD, Burke RC, Han X, Zhang F, McMurtry SA, Colbert JF, Lindsell CJ, Angus DC, Kellum JA. Intravenous fluid resuscitation is associated with septic endothelial glycocalyx degradation. Crit Care. 2019;23(1):1-0. https://doi.org/10.1186/s13054-019-2534-2.

\section{Publisher's Note}

Springer Nature remains neutral with regard to jurisdictional claims in published maps and institutional affiliations.

Ready to submit your research? Choose BMC and benefit from:

- fast, convenient online submission

- thorough peer review by experienced researchers in your field

- rapid publication on acceptance

- support for research data, including large and complex data types

- gold Open Access which fosters wider collaboration and increased citations

- maximum visibility for your research: over $100 \mathrm{M}$ website views per year

At $\mathrm{BMC}$, research is always in progress.

Learn more biomedcentral.com/submissions 